\title{
A CLASSE DOS ESTADOS E A CISÃO INTRANSITIVA EM LÍNGUAS TUPÍ-GUARANÍ
}

ANA CRISTINA RODRIGUES DE MATTOS ${ }^{1}$

$U N B, B R A S I L$

https://orcid.org/0000-0002-9595-8056

\begin{abstract}
RESUMO: Os verbos intransitivos têm recebido atenção dos estudos linguísticos desde o início do Século XX, em razão de diferenciarem, em algum aspecto, da morfologia ou da sintaxe de muitas línguas, subclasses com comportamentos distintos. A esse fenômeno se dá o nome genérico de Cisão Intransitiva (CI). Nas línguas Tupi-Guarani (TG), as questões sobre a cisão intransitivam ganham tons ainda mais divergentes, uma vez que não há unanimidade entre os pesquisadores em reconhecer a existência de duas subclasses intransitivas, uma composta por verbos ativos, outra por estativos. Os critérios comumente empregados para distinguir classes lexicais não ajudam a resolver a questão: as línguas $T G$ não apresentam classes formais produtivas de adjetivos, as diferentes classes de palavras compartilham material morfológico e as funções de predicado e argumento não são exclusivas de verbos e nomes, respectivamente. Este artigo tem por objetivo analisar o comportamento das palavras estativas e a cisão intransitiva atestada em quatro línguas da Família Tupi-Guaraní (FTG): o Tapirapé, o Guajá, o Emerillón e o Guaraní.
\end{abstract}

PALAVRAS-CHAVE: intransitividade cindida, tupi-guaraní, estatividade.

ABSTRACT: Intransitive verbs have received lots of attention from linguistic studies since the beginning of the 20th century, due to differentiating, in some aspect of the morphology or syntax of many languages, subclasses with different behaviors. This phenomenon is usually named as Split Intransitivity (SI) In Tupí-Guaraní (TG) languages, this issue is even more complex, as there is no unanimity among researchers in recognizing the existence of two intransitive subclasses, one semantically active and another composed of stative verbs The basic criteria used to distinguish lexical classes do not make this issue any simpler: TG languages have no significant formal class of adjectives, lexical classes share lots of morphological material and predicate and argument functions are not exclusive to verbs and names, respectively. This article focus on analyzing the behavior of stative words and on the intransitive split attested in four TG languages: Tapirapé, Guajá, Emerillón and Guaraní.

KEYWORDS: intransitividade cindida, tupí-guaraní, estatividade.

\footnotetext{
${ }^{1}$ Doutoranda em Linguística pela Universidade de Brasilia. E-mail: acrmattos@gmail.com
} 


\section{Introdução}

Nas línguas da Família Tupí-Guaraní ${ }^{2}$ (FTG), a grande quantidade de morfologia compartilhada entre nomes e verbos (e posposições), a inexistência de uma classe formal produtiva de adjetivos e a sobreposição funcional de nomes e verbos em função argumental e predicativa criam uma dificuldade para se analisar as palavras que designam estados, e é justamente a classificação dessas palavras como nomes ou verbos o ponto crucial para se considerar a existência de duas subclasses intransitivas nessas línguas, uma de verbos denominada de ativos (ou eventivos) e outra de palavras estativas (ou descritivas).

Há autores, como Praça (2007) e Magalhães \& Mattos (2014), que interpretam as palavras estativas, nas línguas que estudam, como uma subclasse intransitiva de verbos descritivos, ou estativos. No entanto, autores como Dietrich (2001) e Rose (2003) consideram que a classe semântica dos estados, conforme denominado por Queixalós (2001), possui natureza nominal. No Guaraní, Dietrich (2001) classifica o comportamento da classe dos estados como semelhante ao dos nomes dependentes ${ }^{3}$, enquanto Rose (2003) postula que os estados formam, no Emerillón, duas subclasses a que ela denomina, seguindo a terminologia e as análises propostas por Couchili, Maurel e Queixalós (2001), nominoides e atributivos.

Debruçaremo-nos aqui sobre essas diferentes perspectivas na análise das palavras estativas no que línguas da FTC podem nos ensinar a respeito da intransitividade cindida.

No quadro teórico da tipologia funcional, serão analisadas neste trabalho quatro línguas da Família Tupí-Guaraní: o Tapirapé, o Guajá, o Emerillón e o Guaraní. O Tapirapé e o Guajá são descritos por Praça (2007) e Magalhães \& Mattos (2014) como línguas que apresentam cisão intransitiva por possuírem uma subclasse de verbos intransitivos ativos e outra de intransitivos estativos na qual se enquadram as palavras que possuem semantismo adjetival, também referidas neste trabalho como palavras estativas. No Emerillón, Rose (2003) defende não haver duas subclasses intransitivas, pois considera o comportamento morfossintático de tais palavras como mais próximo ao dos nomes e as divide em duas subclasses diferenciadas: nominoides e atributivos, os primeiros de natureza nominal e os segundos como um grupo de palavras que não tem natureza verbal, nem nominal, nem adjetival ${ }^{4}$. No Guaraní, há diferentes opiniões sobre a cisão. Para as diversas variedades do Guaraní, Dietrich (2001) defende que as palavras estativas sejam nomes similares aos nomes dependentes, diferentemente de Martins (2003), que descreve as raízes estativas da variedade Mbyá do Guaraní como uma subclasse verbal.

\footnotetext{
${ }^{2}$ Grupo de cerca de trinta e cinco línguas para as quais se postula uma origem comum em razão de semelhanças lexicais, morfológicas e sintáticas.

${ }^{3}$ Tratados na literatura como nomes possuiveis.

4 Tal análise para a classe dos estados no Emerillón foi originalmente apresentada em artigo publicado em 2001 por Couchili, Maurel e Queixalós, em cuja análise se baseia Rose (2003).
} 
Ao compararmos alguns aspectos morfossintáticos dessas línguas ${ }^{5}$, encontramos descrições que incluem, em uma língua, uma determinada raiz na classe dos nomes, enquanto a raiz cognata em outra língua é descrita como pertencente à classe dos verbos. Os exemplos 1 e 2 ilustram bem a questão. O primeiro é do Tapirapé, em que a raíz ãkow é descrita por Praça (2007) como verbo descritivo 'estar quente', e o segundo é do Emerillón, em que a raíz aku é descrita por Rose (2003) como nominoide (uma subclasse dos nomes) 'quente', 'calor'.

1. ne $=\varnothing$-pir-ãkow

2SG.II=R-pele-estar.quente

'Você está com calor?'

(lit. você está com a pele quente?) (Praça, 2007:171)

2. $\varnothing=\mathbf{a k u}$

3.II-calor

'Faz calor (está quente) tã'e verbo intransitivo descritivo

INTER

nominoide

(Rose, 2003:375)

Em razão desse tipo de divergência nas descrições das línguas TG, busca-se reunir propriedades ou processos morfossintáticos comuns às quatro línguas e que possam fornecer indícios de que as palavras estativas possuem comportamento formal mais compatível com temas verbais ou nominais. Para isso, é necessário descartar como critério de pertencimento a uma classe ou outra os processos morfológicos comuns a ambas as classes. O objetivo é observar a maneira como essas línguas contrastam morfossintaticamente verbos e nomes, a fim de reunir pistas de que as palavras estativas pertencem a uma classe ou outra, sempre pensando em termos de características prototípicas e não em propriedades necessárias e suficientes.

\section{A cisão intransitiva}

Cisão intransitiva $(\mathrm{Cl})$ é um termo empregado para denominar a existência de duas subclasses de verbos intransitivos, que contrastam em algum aspecto, evidenciando, portanto, um comportamento distinto entre elas. A distinção no comportamento desses verbos emerge de maneiras muito diversificadas nas línguas do mundo, seja explícita na morfologia da língua - tal como na marcação de caso ou na codificação dos argumentos - seja subjacente a determinados mecanismos sintáticos - seleção de verbos auxiliares, construção de causativas, inversões na ordem, entre outros. O fenômeno que aqui denominamos Cisão Intransitiva $(\mathrm{Cl})$ aparece sob muitos outros nomes na literatura linguística,

\footnotetext{
${ }^{5}$ CAUS: causativo / COP: cópula / DEM: demonstrativo / DESID: desiderativo / EVID: evidencial / FOC: focalizador / FUT: futuro nominal / GER: gerúndio / HAB: habitual / I: marcas de pessoa da série I / II: marcas de pessoa da série II / III: marcas de pessoa da série III / INTER: partícula interrogativa / LOC: locativo / NEG: negação / NOMN: nominalizador / PASS: passado nominal / PL: plural / POS: posposição / PRED: sufixo predicador / PRO: pronome / R: marca de adjacência / REF: referencial / REFER: morfema referenciante / SG: singular
} 
entre eles cisão ativo-estativo, sistemas agentivos, sistemas agentivospacientivos, Split-S, alinhamento nominativo-absolutivo e línguas de tipologia ativa.

O comportamento dos verbos intransitivos tem instigado linguistas desde as primeiras décadas do século XX, quando Sapir (1917), ao refutar a análise de Uhlenbeck (1916) de que a cisão morfológica na marcação de pessoa estava relacionada ao caráter essencialmente passivo das construções transitivas de diversas línguas indígenas americanas ${ }^{6}$, denominou de "ativas" as formas intransitivas que correspondiam aos sujeitos das transitivas e de "inativas" as formas correspondentes aos objetos das transitivas, instituindo a tradição, que viria a perdurar praticamente pelas cinco décadas seguintes, de se associar a oposição semântica entre verbos ativos e inativos à cisão na classe dos intransitivos.

As motivações semânticas para o comportamento cindido dos intransitivos começaram a ser questionadas pelos pesquisadores da Gramática Relacional, que adotaram e adaptaram as ideias de Sapir para postular motivações sintáticas para as cisões morfológicas, como a Hipótese Inacusativa (HI), de Perlmutter (1978), posteriormente desenvolvida por Búrzio7 (1981).

Até os anos 1970 as línguas de subclasses intransitivas eram consideradas como subtipos dos sistemas ergativos, e é Klimov (1974) quem inicia a tradição de se considerar essas línguas como um terceiro tipo de sistema, diferenciado dos alinhamentos principais NOM-ACU e ERG$A B S$, pelo fato de essas línguas se organizarem não em função da atribuição de caso nominativo ou ergativo ao sujeito, mas em função da oposição entre participantes semanticamente ativos e não ativos.

No início dos anos 2000, as línguas de intransitivo cindido também foram denominadas de "línguas de alinhamento semântico", conforme proposto por Wichmann (2008), e na literatura sobre o tema predominam as análises que enxergam a cisão como um fenômeno determinado pela semântica do verbo, principalmente pelo seu aktionsart (contraste ativo/estativo) e pelo papel semântico desempenhado pelo participante único.

A todas as denominações de natureza semântica para as cisões intransitivas faz-se a crítica de que elas implicam, em detrimento de toda a polêmica sobre suas motivações, uma decisão prévia que exclui a possibilidade de cisões meramente lexicais, ou por existirem, de fato, cisões semanticamente arbitrárias, ou pela eventual impossibilidade de rastrear tais motivações em razão de processos históricos de lexicalização e/ou gramaticalizações (Creissels 2008:142).

\footnotetext{
${ }^{6}$ Wichmann (2008:05).

${ }^{7}$ Burzio leva esses estudos para o quadro teórico da Gramática Gerativa, denominando-a Hipótese Ergativa
} 


\section{As classes de palavras}

Ao definir classes de palavras lexicais, Givón (2001) reconhece como classes universais os nomes, verbos, adjetivos e advérbios. A partir da noção de protótipo, em oposição ao sistema tradicional de características distintas, ele defende que o pertencimento de uma palavra a uma determinada classe depende não de um único, mas da combinação de critérios semânticos, morfofonológicos e sintáticos. Os critérios semânticos propostos pelo autor são relacionados entre si e compõem, juntos, grupos de conceitos semânticos a que ele denomina escala de estabilidade temporal, segundo a qual se distinguem as classes de palavras.

A morfologia gramatical é, segundo Givon (2001), critério igualmente importante para definir o pertencimento de uma raiz a uma determinada classe. A morfologia associada aos nomes geralmente inclui marcadores de gênero e classificadores, marcadores de número, artigos, marcas de caso em âmbito semântico (agente, paciente etc.) ou sintático (sujeito, objeto etc.), pronomes possessivos. As características morfológicas mais comumente associadas aos verbos incluem tempo, aspecto e modalidade, negação, pronomes e concordância (com ou sem pronomes) e morfologia de ajustes de valência, entre outras.

Queixalós (2001) acrescenta que o fundamento da distinção entre nomes e verbos se dá pela superposição dos planos morfológico, sintático, semântico e pragmático. No plano da forma, é o material explicito, por exemplo, tempo/aspecto do lado dos verbos, gênero/pessoa do lado dos nomes que vai orientar a afiliação da classe dos estados com a dos nomes ou a dos verbos. No plano sintático, é a aptidão de certas raízes em funcionarem primariamente como argumento ou como predicado. No plano semântico, em linhas gerais, a polarização se dá em termos da oposição entre eventos e estados e, por fim, no plano pragmático, certas raízes são mais aptas para introduzir no discurso participantes manipuláveis (tema) e outras para relatar eventos (rema).

Delancey (2001:41) defende verbos e nomes como as únicas classes universais e fontes diacrônicas de todas as outras, e a não universalidade da classe dos adjetivos, separando, em sua análise, forma de função. Para os adjetivos, o que ele apresenta como universal é a existência de uma categoria de "palavras que conceituam propriedades", que podem vir a se realizar como adjetivos nas línguas que formam adjetivos, ou como uma subclasse de nomes ou verbos nas línguas que não formam adjetivos.

Dixon (1977:10) reconhece a existência de línguas sem uma classe definida de adjetivos e agrupa em sete tipos semânticos as palavras que conceituam propriedades: dimensão, propriedades físicas, cor, propensão humana, idade, juízo de valor e velocidade. Quase três décadas depois, Dixon (2004) passa a defender que é possível encontrar uma classe de adjetivos em todas as línguas humanas, mas que ela não é homogênea. Haveria, portanto, segundo o autor, dois tipos de adjetivos, um que desempenha função de modificador de SNs e apresenta propriedades mais tipicamente nominais, e um outro tipo de adjetivo que 
institui núcleo de predicados intransitivos e expressa propriedades relativas a entidades, se comportando, portanto, de maneira mais semelhante a verbos.

\section{A classe dos estados nas línguas Tupí Guaraní}

A classe dos estados costuma ser expressa por adjetivos nas línguas que formalizam classes de adjetivos, tal como o fazem boa parte das línguas europeias, por meio de formas verbais finitas ou por estruturas intermediadas por cópula. As línguas da Família TG têm sido descritas como línguas que não possuem classe formal de adjetivos numericamente relevante. Além disso, estruturas intermediadas por cópula não costumam ser produtivas nessas línguas.

Em línguas sem adjetivos, a expressão dos estados se dá por meio de raízes verbais ou de raízes nominais, e é neste ponto em que se evidencia como um grande desafio a análise da classe dos estados nas línguas TG. Ainda que combinados, os critérios semânticos, morfológicos e sintáticos mais frequentemente encontrados na literatura linguística não dão conta de resolver satisfatoriamente a questão da classificação das palavras estativas.

Em termos semânticos, a fronteira entre eventos e estados nem sempre é bem delineada. Segundo Mithun (1991), há muitos processos de gramaticalização nas línguas que obscurecem esses limites, especialmente quando um verbo tem seu sentido alterado ou ampliado, mas permanece com a mesma morfologia de um estágio anterior da língua. No Guarani, por exemplo, algumas raízes permitem flexão com os dois paradigmas de pessoa, com mudança de sentido. A raíz karú 'comer', se flexionada com marcas de pessoa da Série I, expressa uma ação, um evento 'almoçar ou jantar'. Se flexionada com as marcas pessoais da Série II expressa um estado, 'ser guloso'. O mesmo se dá com o verbo kapú, que flexionado com a Série I significa 'ficar bêbado' e flexionado com a Série II significa 'ser alcoólatra'.

Ainda que seja possível distinguir raízes verbais de nominais, as línguas da Família TG apresentam muitos processos morfossintáticos que atuam no nível dos predicados, e não das raízes, e há muita morfologia gramatical compartilhada por diversas classes de raízes, tais como a negação, seja sentencial ou de constituinte, a flexão relacional, a flexão com o sufixo $a^{-{ }^{8}}$, a reduplicação, as nominalizações de predicados por meio de *-ßape e a causativização de predicados intransitivos.

Acerca das funções sintáticas típicas de argumento e predicado, uma das propriedades mais caracterizadoras das línguas da FTG é o fato

\footnotetext{
${ }^{8}$ Ainda que o sufixo - $a$ ocorra na maioria das línguas da FTG junto a raízes nominais, há línguas em que ele aparece junto a raízes verbais, tal como o Tapirapé.

${ }^{9}$ Forma reconstruída para o PTG (Proto-Tupí-Guaraní) por Jensen, (1998), equivalente aos sufixos -ma 'e em Emerillón, -ma'a em Guajá, -ama'e em Tapirapé, -va'e no Guaraní, entre outras formas cognatas, sempre muito produtivas nas línguas TG.
} 
de a função predicativa não ser exclusiva de verbos: como regra geral ${ }^{10}$, nessas línguas os nomes podem instituir núcleo de predicado sem intermediação de verbos copulativos e sem necessidade de morfologia derivacional. A hipótese de Queixalós (2006) é de que as línguas da FTG apresentam um padrão de organização morfossintática condizente com o que Launey (1994), apud Queixalós (2001), descreveu como omnipredicatividade em seus estudos sobre o Nahuatl. As línguas da FTG parecem descender de uma língua ancestral comum cujas entradas lexicais das principais classes de palavras tinham como função primária a predicação, sendo a função argumental secundária, derivada da primeira. Assim, nem sempre é possível relacionar sintaticamente essas duas classes de palavras às funções exclusivas de argumento e predicado, respectivamente.

A discussão sobre a existência ou não de cisão intransitiva nas línguas da FTG se deve às diferentes interpretações dadas às palavras que designam estados, tais como ast, interpretado por Dietrich (2001) no Guaraní como 'doença', e por Mithun (1991), também no Guaraní, como 'estar doente'.

Alguns pesquisadores consideram a classe dos estados nas línguas TG como uma subclasse de nomes. Grande parte dessas palavras possuem, de fato, um semantismo que mais as aproxima, de acordo com a escala de estabilidade temporal de Givón (2001), dos substantivos, especialmente quando as traduzimos para línguas como o português. Dietrich (2001:28), por exemplo, defende que no Guaraní as palavras estativas são nomes porque são "substantivos com valor predicativo", "trata-se da expressão de substâncias, de seres, objetos e ideias abstratas". Outros dois critérios que o autor usa para classificar os estados como nomes são: 1) o fato de que os estados compartilham com posposições e com uma determinada subclasse de nomes o mesmo paradigma pronominal; 2) as palavras que designam estados podem assumir função sintática de sujeito, complemento de objeto e complemento de circunstância, além de predicar.

Diferentemente, há pesquisadores que classificam tais palavras como verbos principalmente em razão do seu comportamento morfossintático revelar-se semelhante ao dos verbos intransitivos em termos de valência e de possibilidades de flexão com determinados morfemas, exclusivos de verbos da Família TG, tais como nominalizadores. Seki (2001), por exemplo, relaciona a classe dos estados em Kamaiurá com a descrição dos sete tipos semânticos propostos por Dixon (1977) para os adjetivos, e classifica os estados como uma subclasse de verbos, a que ela denomina descritivos.

Queixalós (2001) levanta a possibilidade de que a identificação da classe dos estados como nome em uma língua e como verbo em outra língua geneticamente aparentada seja um indício de evolução diacrônica em curso:

\footnotetext{
${ }^{10}$ Além da predicação direta, algumas línguas também apresentam predicação nominal intermediada por cópula, como o Emerillón e o Kamaiurá.
} 
Não podemos, portanto, escapar à dimensão diacrônica, que levanta a questão de saber se a classe dos estados possui alguma realidade formal em uma etapa atestada ou reconstruível, por exemplo, ao se realizar como uma classe sintática que não é nome nem verbo, ou em se constituir em uma classe caracterizada por uma dupla vocação, verbal e nominal (QUEIXALÓS, 2001:06).

\section{As marcas de pessoa}

O sistema de marcação de pessoa nas línguas da FTG é descrito em cada língua como tendo quatro grandes paradigmas compostos de clíticos e afixos. Costumam ser denominados Séries e numerados de I a IV. Há também um paradigma distinto de pronomes livres, ou independentes, de que não trataremos neste trabalho. Como será focalizada a cisão intransitiva em orações independentes e no modo indicativo, as marcas de pessoa das séries III e IV ficarão, por ora, omitidas: trataremos apenas das chamadas Séries I e II, sem aprofundar no debate sobre sua natureza prefixal ou clítica.

Os pesquisadores que estudam as línguas TG concordam unanimemente que as marcas da Série I, indicadas na Tabela 1, são exclusivas de verbos. Elas se afixam a raízes verbais de verbos transitivos, indicando o participante com propriedades semânticas de agente (A), e a raízes intransitivas, indicando o participante único. Não há divergência em relação à distribuição desta série, incompatível com nomes, posposições e palavras que designam estados.

Tabela 1 - As marcas de pessoa da Série I

\begin{tabular}{|c|c|c|c|c|c|}
\hline Série I & PTG (1) & Tapirapé (2) & Guajá (3) & Emerillón (4) & Guaraní (5) \\
\hline $1 \mathrm{Sg}$ & $* a-$ & ã- & a- & a- & a- \\
\hline $1 \mathrm{PI}-\mathrm{In}$ & *já- & $x i-$ & $x i-$ & tsi- & já- ña- \\
\hline 1PI-ExI & *oro- & ara- & ari- & olo- & ro- \\
\hline $2 \mathrm{Sg}$ & *ere- & ere- & ari- & ele- & re- \\
\hline $2 \mathrm{PI}$ & *pe- & pe- & $\sim p i-$ & pe- & pe- \\
\hline $3 P$ & $*_{0}$ & a- & $\varnothing$ & o- & o- \\
\hline \multicolumn{2}{|c|}{ Fontes de dados: } & \multicolumn{2}{|c|}{ 1) PTG - Jensen (1999) } & \multicolumn{2}{|c|}{ 2) Tapirapé - Praça (2007) } \\
\hline \multicolumn{2}{|c|}{ 3) Guajá - Magalhães (2007) } & \multicolumn{2}{|c|}{ 4) Emerillón - Rose (2003) } & \multicolumn{2}{|c|}{ 5) Guarani - Dietrich (2001) } \\
\hline
\end{tabular}

Nos verbos intransitivos que denotam eventos, atividades ou processos, e possuem como argumento único um participante com características semânticas de agente e propriedades sintáticas típicas de sujeito" , os prefixos da Série I indicam o SA, conforme exemplos 3 do Guajá e 4 do Tapirapé:

\footnotetext{
${ }^{11}$ Posição privilegiada na hierarquia de acessibilidade, existência independente, pouca propensão ao apagamento e autonomia da referência (KEENAN, 1972).
} 
3. jaha a-wata ka'a r-ipi

eu 1SG.I-andar mata R.por

'Eu andava pelo mato' (Magalhães, 2007:107)

4. ã-xãok we-ka-wo

1SG.I-banhar 3.III-estar-GER

'estou banhando'

(Praça, 2007:96)

No entanto, tal unanimidade não existe em relação às marcas pessoais da Série II. Essas marcas de pessoa têm sido analisadas de maneiras diversas nos estudos de línguas TG:

- Exclusivo de nomes e posposições, e vetado aos verbos (Dietrich, 2001).

- Compartilhado por nomes, posposições e verbos transitivos, marcando o argumento objeto (Rodrigues 1996, Rose 2003, Cabral 2009).

- Compartilhado por nomes, posposições, verbos transitivos, marcando o argumento objeto, e marcando o argumento único de verbos intransitivos estativos (Seki 2001, Praça 2007, Cruz 2011, Magalhães \& Mattos 2014).

Conforme ilustrado na Tabela 2, com exceção da marca de terceira pessoa, que tem natureza prefixal, as marcas da série II se cliticizam à raíz intermediadas por um prefixo relacional $r$-:

Tabela 2 - As marcas de pessoa da Série II

\begin{tabular}{|c|c|c|c|c|c|}
\hline Série II & PTG (1) & Tapirapé (2) & Guajá (3) & Emerillón (4) & Guaraní (5) \\
\hline $1 \mathrm{Sg}$ & ${ }^{*}$ ce & $x e=$ & há= & $e=$ & che- \\
\hline $1 P I-I n$ & *jane & xane= & are $=$ & nõde & ñande- \\
\hline 1PI-ExI & *ore & are $=$ & are $=$ & olone= & ore- \\
\hline $2 \mathrm{Sg}$ & $*_{\text {ne }}$ & ne $=$ & $\mathrm{ni}=$ & $\mathrm{de}=$ & nde- $\sim$ ne- \\
\hline $2 \mathrm{PI}$ & ${ }^{*}$ pe & $p e=$ & pĩ= & $\mathrm{pe}=$ & peẽ- \\
\hline $3 P$ & $*_{\mathrm{i}-,}, *_{\mathrm{h}-}$ & $\mathrm{i}-\sim \varnothing \sim \mathrm{t}-$ & $\mathrm{i}-\sim \mathrm{h}-$ & $\mathrm{i}-(\sim \varnothing \sim \mathrm{t}-)$ & $\varnothing$ \\
\hline
\end{tabular}

$\begin{array}{lll}3) \text { Guajá - Magalhães (2007) } & \text { 4) Emerillón - Rose (2003) } & \text { 5) Guaraní - Dietrich (2001) }\end{array}$

Fonte: elaboração própria

Os verbos transitivos das orações principais levam a marca da série II para indicar o participante com propriedades prototípicas de paciente $^{12}$, quando este está interagindo com um participante mais baixo

\footnotetext{
${ }^{12}$ Ser submetido a uma mudança de estado, ser afetado por outro participante, ser relativamente estacionário em relação ao outro participante, não ter existência independente do evento nomeado pelo verbo ou não ter qualquer existência (DOWTY, 1991)
} 
na hierarquia de referência vigente em cada uma das línguas, tal como no exemplo 5, do Guajá:

5. Jaha ni=n-ixa ha=Ø-kere r-ipi

$\mathrm{Eu} \quad 2 \mathrm{SG} . \mathrm{II}=\mathrm{R}-\mathrm{ver}$ 1SG.II=R-dormir R-por

'eu vi você no meu sonho' (Magalhães, 2007:54)

(lit. 'eu vi você no meu dormir')

Nas palavras que designam estados, a Série II indica o participante a quem aquele estado se refere. Sintaticamente ele é o argumento único de um predicado intransitivo, com propriedades semânticas de nãoatividade, tal como no exemplo 6, do Tapirapé:
6. Tokyn-a
i-kywer
Tokyna-REFER
3.II-ser.magra
'Tokyna é magra'
(Praça, 2007:99)

Os nomes dependentes, tradicionalmente conhecidos como nomes inalienavelmente possuídos, também se flexionam com a marca de pessoa da Série II, indicando o possuidor, tal como no exemplo 7, do Guajá:

7. ha=r-a'yr-a Ø-aho i-pyry

1SG.II=R-filho-REFER 3-ir 3-junto

'meu filho foi para junto dele' (Magalhães, 2007:14)

A série II também aparece nas posposições, marcando a relação entre o núcleo e seu objeto, seja este um SN pleno, como no exemplo 8 , ou uma marca de pessoa, tal como no exemplo 9, ambos do Tapirapé:
8. xãwar-a
a-yj cachorro-REFER
3.I-correr
wyrãkaj-a
r-ewiri
'o cachorro correu atrás da galinha
galinha-REFER
R-POS
9. $\mathrm{xe}=\mathrm{r}$-eymãw-a
1SG.II=R-animal.doméstico-REFER
mĩ a-ka
(Praça, 2007:34)
Meu cachorro está sempre comigo
HAB 3.I-estar R-POS
(Praça, 2007:34)

\section{O Tapirapé}

A respeito das classes de palavras que despertam nosso interesse no Tapirapé, Praça (2007) menciona a existência de duas classes de nomes, uma composta por itens lexicais plenos e outra por pronomes, e dois tipos de verbos, a depender de sua valência: transitivos (V2) e intransitivos $(\mathrm{V} 1)$, estes últimos distribuídos em duas subclasses, intransitivos ativos e descritivos, sendo esta última a subclasse de verbos em que se incluem, no Tapirapé, as palavras que designam estados. Os 
Espaço Ameríndio

exemplos 10 e 11 ilustram o comportamento diferenciado na seleção do paradigma de pessoa entre as duas subclasses de verbos intransitivos, os ativos e os estativos, respectivamente:

10. ã-xãok

1sg.I-banhar

'estou banhando'

11. Tokyn-a

Tokyna-REFER

'Tokyna é magra' we-ka-wo

3.III-estar-GER

(Praça, 2007:96)

i-kywer

3.II-ser.magra

(Praça, 2007:99) verbo ativo

verbo estativo

Apesar da flexibilidade funcional de nomes e verbos em relação à função argumental e predicativa, e do compartilhamento da Série II entre diversas classes lexicais, no Tapirapé, as duas classes de raízes são, segundo Praça (2007), identificáveis, em razão da existência de material morfológico privativo de cada classe, conforme demonstrado na tabela 3 , onde estão listados os morfemas que se ligam exclusivamente a raízes nominais, e na tabela 4, que traz os morfemas que se vinculam apenas a raízes verbais:

Tabela 3 - morfologia exclusivamente nominal do Tapirapé

\begin{tabular}{|c|c|c|c|c|c|c|c|}
\hline & \multirow{2}{*}{ Função } & \multirow{2}{*}{\begin{tabular}{|c|} 
Morfologia \\
morfemas/alomorfes
\end{tabular}} & \multicolumn{2}{|c|}{ Nomes } & \multirow{2}{*}{ Estados } & \multicolumn{2}{|c|}{ Verbos } \\
\hline $0^{\circ}$ & & & Absol. & Depen. & & V1 Ativ. & v2 \\
\hline \multirow{5}{*}{ 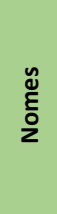 } & Coletivizador & -kwer & + & - & - & - & - \\
\hline & Passado Nominal & -kwer, wer, -er & + & + & - & - & - \\
\hline & Futuro Nominal & -rym & + & + & - & - & - \\
\hline & Similaridade & -ryn & + & + & - & - & - \\
\hline & Antiguidade & -ymyn & + & + & - & - & - \\
\hline
\end{tabular}

Fonte: elaboração própria

Tabela 4 - morfologia exclusivamente verbal do Tapirapé

\begin{tabular}{|c|c|c|c|c|c|c|c|}
\hline \multirow{2}{*}{$\mathrm{c}^{0^{5^{5}}}$} & \multirow{2}{*}{ Função } & \multirow{2}{*}{\begin{tabular}{|c|} 
Morfologia \\
morfemas/alomorfes \\
\end{tabular}} & \multicolumn{2}{|c|}{ Nomes } & \multirow{2}{*}{ Estados } & \multicolumn{2}{|c|}{ Verbos } \\
\hline & & & Absol. & Depen. & & V1 Ativ. & v2 \\
\hline \multirow{8}{*}{ 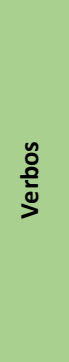 } & Derivação de nomes deverbais & -ãw 〜-taw & - & - & + & + & + \\
\hline & Contrafactual & -werer & - & - & + & + & + \\
\hline & Desiderativo & -patãr & - & - & + & + & + \\
\hline & Potencialidade, habilidade & -kwããw & - & - & $?$ & + & + \\
\hline & Apreciativo & -kãto & - & - & + & + & + \\
\hline & Imperativo afirmativo & e- / pe- & - & - & + & + & + \\
\hline & Imperativo negativo & ere- pexe & - & - & + & + & + \\
\hline & Prefixos da Serie I & ã, $x i$, ara, ere, pe, a & - & - & - & + & + \\
\hline
\end{tabular}

Fonte: elaboração própria

Conforme pode ser observado, entre os morfemas indicados por Praça (2007) como morfologia gramatical exclusiva de raízes nominais, nenhum parece ser compatível com verbos ou com as palavras que designam estados. Além disso, ao observarmos a morfologia dos verbos, 
organizada na tabela $4^{13}$, encontramos inúmeros pontos de convergência entre o comportamento morfossintático das raízes estativas e o dos verbos intransitivos ativos, fazendo pender a classe dos estados para o lado dos verbos.

\section{O Guajá}

A respeito de nomes e verbos, classes que despertam nosso interesse neste estudo, Magalhães (2007) caracteriza morfologicamente os nomes como a única classe capaz de admitir flexão com o sufixo - $a$ e com os sufixos de atualização nominal -ker -er e -rỹm, também conhecidos como passado e futuro nominal, atribuindo, respectivamente, àquela entidade a que se liga a característica de existência passada ou de possibilidade de existência futura.

Sobre as raízes verbais na língua Guajá, Magalhães \& Mattos (2014) identificam dois tipos, a depender da quantidade de argumentos em sua estrutura argumental: transitivos (V2) e intransitivos (V1). Os transitivos são sempre ativos e associados às marcas de pessoa da Série I, respeitada a HR, que indicam o agente prototípico, o iniciador da ação expressa pelo verbo. As marcas da Série II estão associadas ao paciente, ao receptor ou destinatário da ação expressa pelo verbo. Os intransitivos se dividem em duas subclasses, uma que compreende os verbos eventivos, cuja expressão da categoria de pessoa se dá por meio da Série I e outra que compreende os verbos estativos, cuja expressão da categoria pessoa se dá pela Série II, intermediada pela marca de adjacência $\mathrm{R}^{14}$. Semanticamente, as duas subclasses diferem da seguinte maneira: verbos ativos possuem um participante único com propriedades prototípicas de agente, enquanto o participante único dos estativos é o detentor das propriedades, qualidades ou estados existenciais expressos pelo verbo.

Tal como Praça sobre o Tapirapé, Magalhães (2007) afirma ser possível distinguir raízes verbais de nominais no Guajá, em razão da existência de material morfológico privativo de cada uma, conforme demonstrado na tabela 5 , que lista os processos exclusivos da classe de nomes, vetados aos verbos, e na tabela 6 , que traz morfologia privativa de raízes verbais.

Tabela 5 - morfologia exclusivamente nominal do Guajá

\begin{tabular}{|c|c|c|c|c|c|c|c|}
\hline & \multirow{2}{*}{ Função } & \multirow{2}{*}{$\begin{array}{c}\text { Morfologia } \\
\text { morfemas/alomorfes }\end{array}$} & \multicolumn{2}{|c|}{ Nomes } & \multirow{2}{*}{ Estados } & \multicolumn{2}{|c|}{ Verbos } \\
\hline$a^{\sigma^{\circ}}$ & & & Absol. & Depen. & & V1 Ativ. & $\mathrm{v} 2_{2}$ \\
\hline \multirow{5}{*}{$\begin{array}{l}\stackrel{\mathscr{u}}{E} \\
\dot{0}\end{array}$} & Coletivizador & -kér -ér & + & + & - & - & - \\
\hline & Passado Nominal/Atualização nominal retrosp. & -kér -ér & + & + & - & - & - \\
\hline & Futuro Nominal & -rỹm & + & + & - & - & - \\
\hline & Similaridade & -rỹn & + & + & - & - & - \\
\hline & Antiguidade & -mỹn & + & + & - & - & - \\
\hline
\end{tabular}

Fonte: elaboração própria

\footnotetext{
${ }^{13}$ A falta de informação explicita no trabalho fonte sobre a compatibilidade com determinado morfema ou processo morfológico foi indicada com “?”.

${ }^{14}$ Tradicionalmente tratado na literatura linguística como prefixo relacional.
} 
Tabela 6 - morfologia exclusivamente verbal do Guajá

\begin{tabular}{|c|c|c|c|c|c|c|c|}
\hline \multirow{2}{*}{$0^{00^{55^{2}}}$} & \multirow{2}{*}{ Função } & \multirow{2}{*}{\begin{tabular}{|c|} 
Morfologia \\
morfemas/alomorfes \\
\end{tabular}} & \multicolumn{2}{|c|}{ Nomes } & \multirow{2}{*}{ Estados } & \multicolumn{2}{|c|}{ Verbos } \\
\hline & & & Absol. & Depen. & & v1 Ativ. & v2 \\
\hline \multirow{9}{*}{ 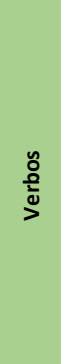 } & Causativização predicados Intransitivos & ma- -mi & - & - & + & + & - \\
\hline & Derivação de nomes deverbais & -ahá- -á- & - & - & + & + & + \\
\hline & Contrafactual & neme'ẽ & - & - & + & + & + \\
\hline & Desiderativo/Futuro (querer)/Prospectivo & -tá & * & * & + & + & + \\
\hline & Potencialidade, habilidade & -kwá & - & - & + & + & + \\
\hline & Apreciativo & -katy -kata & - & - & + & + & + \\
\hline & Imperativo afirmativo & a- /pa- & - & - & + & + & + \\
\hline & Imperativo negativo & a-/pa- & - & - & + & + & + \\
\hline & Prefixos da Serie I & a- ari-ari xi-pi- $\varnothing$ & - & - & - & + & + \\
\hline
\end{tabular}

Fonte: elaboração própria

É importante observar duas regularidades a partir das tabelas acima apresentadas: a primeira é que os processos listados como privativos aos nomes, listados nas tabelas 3 e 5, do Tapirapé e Guajá, respectivamente, são vetados aos verbos e às palavras que designam estados; a segunda é que a maioria dos processos morfológicos atribuídos exclusivamente aos verbos ${ }^{15}$ e vetados aos nomes, tal como demonstrado nas tabelas 4 e 6, do Tapirapé e do Guajá, respectivamente, são licenciados às palavras que designam estados. Resta como exceção a flexão com as marcas de pessoa da Série I, vetada às estruturas estativas.

\section{O Emerillón}

A classe dos estados na língua Emerillón é descrita por Rose (2003) como mais próxima aos nomes e cindida em duas subclasses, denominadas pela autora como nominoides e atributivos. Seguindo a tradição de estudos sobre a FTG instituída por Rodrigues (1996), o critério principal de que Rose (2003) se utiliza para categorizar os verbos é o fato de eles se flexionarem com as marcas de pessoa da Série I, vetado aos nomes.

Assim, a autora subdivide a classe dos verbos em intransitivos e transitivos, os primeiros se flexionando exclusivamente com as marcas de pessoa da Série I e os segundos com as Séries I ou $\mathrm{II}^{16}$, a depender da HR.

Rose (op. cit.), seguindo a proposta de Couchili, Maurel e Queixalós (2002), classifica as palavras descritivas no Emerillón como mais próxima à classe dos nomes, e propõe que elas se diferenciam e, duas subclasses, uma numericamente maior e mais próxima dos nomes autônomos, a que ela denomina nominoides, e um pequeno grupo de palavras denominadas atributivas ${ }^{17}$, que compartilham com os nomes absolutos a propriedade de ocorrer sem flexão com marcas de pessoa,

\footnotetext{
${ }^{15}$ Especialmente aos verbos intransitivos ativos, com os quais as palavras estativas compartilham mais propriedades morfossintáticas.

${ }^{16}$ Marcação do participante agente ou paciente, respectivamente.

17 "Somos, então, confrontados com a existência de uma classe semântica de adjetivos que não se identificam, no plano formal, nem como nomes, nem como verbos, nem como adjetivos" (Couchili, Maurel e Queixalós 2002:12, tradução nossa).
} 
mas cujo padrão morfossintático não permite que sejam classificadas nem como nomes, nem como verbos.

A classificação de parte das palavras que designam estados como nominoides, e não como verbos, se baseia, segundo Rose (2003), na sua compatibilidade com a Série $\mathrm{II}^{18}$ ao instituir núcleo de predicado, tal como demonstrado no exemplo 12, e na sua vocação de funcionar como argumento sem o auxílio de morfologia derivacional, necessária aos verbos nessa função (exemplo 13):

12. d-e-kalai-dzi.

NEG-1SG.II-febre-NEG

'Eu não tenho febre'

13. kalai $\quad 0-k^{\mathrm{w}} \mathrm{a}$

febre

3.I-passar nominoide como núcleo de predicado

(Rose, 2003:48)

nominoide em função de argumento

(Rose, 2003:48)

'Existe uma epidemia de febre'

(lit. 'a febre passa')

Há razões, no entanto, que permitem questionamentos quanto a considerar palavras tais como kalai 'febre' (ou 'estar febril') ou kane?o, 'cansaço' (ou 'estar cansado') como uma subclasse de nomes em Emerillón. A primeira é que existem, de fato, em algumas línguas da FTG $^{19}$, verbos que podem desempenhar função argumental sem auxílio de morfologia derivacional, apesar de eles serem pouquíssimos e normalmente não produtivos nessa função ${ }^{20}$. Outra razão que nos leva a questionar a proximidade dos chamados nominoides com a classe dos nomes é a incompatibilidade dessas palavras com propriedades morfossintáticas normalmente associadas a nomes, tal com 0 pluralizador -kom.

A distribuição deste morfema, detalhada por Rose (2012), associao quase exclusivamente a sintagmas ou raízes nominais, com ocorrência muito restrita em hospedeiros verbais. Definido pela autora como um pluralizador, o morfema -kom se combina com os seguintes temas: nomes absolutos; sintagmas genitivos ${ }^{21}$; pronomes pessoais $\mathrm{e}$ demonstrativos; formas deverbais nominalizadas com o sufixo mape entre outros. Em menor frequência, não preso à raiz, mas como partícula, ele pluraliza o argumento de $3^{a}$ pessoa marcado junto ao verbo transitivo (exemplo 14), e raramente ocorre como pluralizador de sujeito de um verbo intransitivo. Observe-se que o uso exemplificado em 15 parece, em razão da repetição do $-k o m$ em todos os constituintes nominais, estar mais relacionado a condições pragmático-discursivas, do que propriamente sintáticas.

\footnotetext{
${ }^{18}$ Segundo Rose a compatibilidade com a Série II é uma propriedade dos nomes.

${ }^{19}$ Nas mais omnipredicativas, tal como o Tapirapé.

${ }^{20}$ A produtividade de raízes verbais em função de argumento ocorre majoritariamente por formas nominais secundárias, derivadas de raízes verbais por meio do sufixo nominalizador de predicados -ma?ẽ.

${ }^{21}$ Indicando o plural do nome dependente, da marca de pessoa ou de ambos.
} 


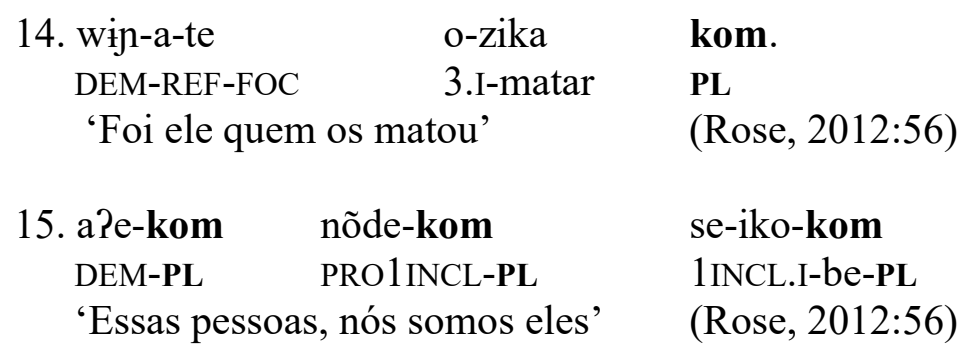

A questão da incompatibilidade dos nominoides com o morfema pluralizador-kom, produtivamente associado a temas não verbais, busca justificar a existência de uma subclasse de palavras que compartilham propriedades com os nomes, mas não são propriamente nomes, e sim nominoides. No entanto, tal incompatibilidade com o sufixo-kom, antes de diferenciar nominoides de nomes, parece aproximar as palavras que designam estados, no Emerillon, das raízes verbais, que exibem outro tipo de marcação de plural, com -on em posição final.

Outra propriedade morfológica dos nominoides apresentada por Rose (2003), a negação sentencial, nada revela sobre o pertencimento deles à classe dos nomes ou dos verbos, pois no Emerillón, tal como em praticamente todas as línguas da FTG, a morfologia da negação, seja ela no nível da oração (por meio de $d=\ldots-i)$, ou de constituintes específicos, (por sufixação com -i), é transcategorial, ou seja, compartilhada por predicados cujos núcleos podem ser de diferentes classes lexicais.

A compatibilidade dos nominoides com o morfema contínuo -o, que marca "o aspecto contínuo de uma ação ou de um estado" (Rose, 2003:431) em sujeito de $3^{\text {a }}$ pessoa, produtivo em verbos, mas não em nomes, também parece aproximá-los da classe dos verbos. Tal compatibilidade com raízes verbais também se deve ao fato de o morfema - o jamais aparecer em um elemento anterior ao predicado. Como a ordem canônica das línguas TG é de verbo final, o uso do -o com raízes nominais fica provavelmente restrito a objetos pospostos ao núcleo do predicado, menos frequentes na língua Emerillon, cuja ordem predominante é OV.

A causativização por meio do prefixo bo- $(\sim m o-\sim m \tilde{o}$, dependendo da raiz) é exclusiva de temas intransitivos. É um morfema frequente e produtivo em Emerillón e sintaticamente consiste na introdução um novo sujeito agente, causador do evento, enquanto o outro participante, o causado, é agente da ação e sintaticamente ocupa função de objeto. Resulta da causativização com bo- uma estrutura divalente, tal como nos exemplos 16 e 17:

16. o-zaug.

3.I-se.banhar

Ele se banha (Rose, 2003:358)

17. wane idze a-mo-zaug

bem PRO1SG 1SG.I-CAUS-se.banhar

Eu, eu faço ela se lavar bem (Rose, 2003:358) 
Segundo Rose (2003), alguns nominoides são causativizados somente com o prefixo bo-, da mesma forma que as raízes verbais, e outros podem levar a dupla marcação bo-... -okal, própria de temas transitivos ou já transitivizados por bo-, obrigatório na causativização de raízes nominais. No entanto, Rose (2003:50) esclarece em nota de rodapé que "todos os nominóides parecem poder ser causativizados unicamente com o bo-", o que os aproxima da classe dos verbos, até porque esse tipo de operação de aumento de valência nas línguas TG é bastante comum, e qualquer raiz monovalente já causativizada com o prefixo bo- passaria a ser divalente e poderia, em princípio, ser novamente causativizada por meio de -okal.

A outra subclasse de palavras em que se realizam os estados na língua Emerillón, os atributivos, são, segundo Rose (op.cit), uma classe mais complexa, pois sua vocação principal não a aproxima nem dos nomes, nem dos verbos, nem dos adjetivos. Na representação das classes lexicais como um continuum, essas palavras estariam fora do eixo verbonominal prototípico, constituindo uma classe marginal cuja denominação faz referência à principal função dessas palavras: explicitar o tipo de propriedades atribuidas.

Em linhas gerais, Rose (2003) postula, seguindo Couchili, Maurel e Queixalós (2002), que a distinção entre atributivos e nomes (e, consequentemente, entre atributivos e nominoides) se dá pelo fato de eles não poderem aparecer associados a uma marca de pessoa. A raiz puku 'Iongo', por exemplo, aparece sozinha, e não flexionada com a Série II, conforme era de se esperar de uma raiz nominal. A forma '*i-puku', flexionada com índice de $3^{a}$ pessoa é considerada agramatical.

Assim, se à primeira vista é possível pensar que os atributivos são utilizados como predicados, a autora defende que essa não é sua vocação, por eles serem "incompatíveis com os índices de pessoa, necessários aos verbos e nomes para que possam predicar" (2003:54), e são, na maior parte do tempo, incapazes de predicar diretamente, sem o auxílio de algum suporte morfológico. Todos precisam de cópula para as pessoas intralocutivas, tal como em 18, e alguns necessitam do sufixo $-d z i \sim-i$ para predicar em terceira pessoa, como em 19:

$$
\begin{aligned}
& \text { 18. Tukug a-dzu } \\
& \text { Baixo 1SG.I-COP } \\
& \text { 'Eu sou baixo' (Rose 2003:55) }
\end{aligned}
$$

Em relação às estruturas causativas, os atributivos, tal qual os chamados nominoides, se assemelham aos verbos intransitivos, utilizando apenas a causação com bo-, exclusiva de temas intransitivos (exemplos 20 e 21 ) e vetada aos nomes: 
20. o-bo-tukug

3SG.I-CAUS-court

'Il le raccourcit'

21. o-bo-zaug.

3.I-CAUS-se.baigner

'Il le baigne' atributivo

(Rose, 2003:57)

verbo intransitivo

Em muitas outras línguas Tupi-Guarani há registros de pequenos grupos de palavras de semantismo adjetival e comportamento morfossintático inespecífico de nomes ou verbos. No Kamaiurá, por exemplo, encontramos ocorrências de alguns descritivos ${ }^{22}$ que atribuem qualidades aos termos a que se ligam, sem o auxílio de qualquer ferramenta morfológica, tal como em 22:

\section{2. y'yw-á katu n=o-mopen-ite \\ flecha-N bom NEG=3-quebrar-NEG}

'ele não quebrou a flecha boa (reta)' (Seki 2000:70)

Martins (2003) também relata no Mbyá a existência de um tipo de estrutura com raízes descritivas na qual elementos como porã 'bonito', puku 'grande', mitã 'nova', katu 'bom' e kaxĩ 'cheiroso', entre outros, podem também ocorrer na função de modificador nominal sem marca de pessoa nem prefixo relacional, como no exemplo 23:

23. sái puku

vestido grande

"vestido grande (Martins 2003:94)

Cruz (2011) também identifica no Nheengatú duas subclasses de verbos intransitivos estativos, uma que se flexiona com as marcas da Série II e outra que não se combina com tais marcas. Segundo a autora, semanticamente essas palavras expressam propriedades físicas permanentes, tais como textura, resistência, formato ou tamanho, conceitos como puranga 'ser bonito/bom' e estados não permanentes, como sasi 'estar doente ou sasiara 'estar triste'. Cruz (2011) lista como verbos intransitivos estativos não flexionáveis irawa 'ser amargo', iwate 'ser alto', pinima 'ser colorido', puranga 'ser bonito / bom', puku 'ser comprido', puxuera 'ser feio', saimbe 'ser afiado', sasi 'estar doente', sasiara 'ser triste', seẽ 'ser gostoso', tipi 'ser fundo', este último uma forma aparentemente cognata de tipi 'profundo' do Emerillón, considerado por Rose (2003) como atributivo.

No Emerillón, a possibilidade de flexão dos chamados atributivos com a Série II, a causativização com bo- e o plural com -on, próprio de temas verbais, parece-nos suficiente para considerar muito tênue a distinção entre atributivos e os chamados nominoides. Fazemos, no entanto, a ressalva de que alguns desses itens lexicais apresentam, de

\footnotetext{
${ }^{22}$ Considerados por Seki como uma subclasse de verbos intransitivos.
} 
fato, variação quando em função predicativa, pois alguns podem predicar por meio do sufixo -i ou da flexão com a Série II, e uma pequena quantidade deles é incompatível com a Série II, só podendo exercer função predicativa com a afixação de $-i$.

Com base nas informações disponíveis nos trabalhos de Rose (2003), montamos a tabela 7, que mostra um pouco da morfologia exclusiva de raízes nominais e verbais. Vale mencionar que a maior parte do trabalho de descrição morfossintática do Emerillón empreendido por Rose (2003) está ancorada no nível dos predicados, não apresentando em muito detalhe o que é específico de raízes verbais e nominais. Observase que são compatíveis com os nomes e verbos transitivos (modificando seu complemento objeto) o coletivizador -kom e o sufixo causativizador de temas transitivos -okal, ambos incompatíveis com verbos intransitivos e as palavras estativas.

Tabela 7 - morfologia exclusiva de nomes e verbos no Emerillón

\begin{tabular}{|c|c|c|c|c|c|c|c|c|}
\hline$s^{e}$ & \multirow{2}{*}{ Função } & \multirow{2}{*}{$\begin{array}{c}\text { Morfologia } \\
\text { morfemas/alomorfes }\end{array}$} & \multicolumn{2}{|c|}{ Nomes } & \multicolumn{2}{|c|}{ Estados } & \multicolumn{2}{|c|}{ Verbos } \\
\hline$c^{r^{3}}$ & & & Absol. & Depen. & Atribut & Nomin & Intr.At & Trans \\
\hline \multirow{2}{*}{$\begin{array}{l}\text { ٌ } \\
\text { छे }\end{array}$} & Coletivizador/Pluralizador & -kom & + & + & - & - & - & + \\
\hline & Causativização de temas transitivos & -okal & + & + & - & - & - & + \\
\hline \multirow{3}{*}{ 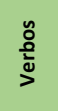 } & Morfema de continuidade & $-\circ$ & - & - & + & + & + & + \\
\hline & Causativização de temas intransitivos & bo- mo- & - & - & + & + & + & - \\
\hline & Prefixos da Serie I & a- tsi- olo- ele- pe- o- & - & - & - & - & + & + \\
\hline
\end{tabular}

Fonte: elaboração própria

Foram selecionados do trabalho de Rose (2003) alguns marcadores de TAM, listados na tabela 8, cuja distribuição suscitou questões impossíveis de serem respondidas no momento. Eles foram descritos pela autora como "atuando no nível dos predicados", mas observa-se em outras línguas TG que suas formas cognatas associam produtivamente suas noções semânticas de tempo, aspecto e modalidade a raízes verbais apenas, e não nominais. São eles: o sufixo de futuro -tal, o sufixo desiderativo -tanẽ e o sufixo completivo -pa, que se associam produtivamente a raízes verbais em muitas línguas da FTG e sua ocorrência nos dados de Rose (2003) confirmam essa tendência, ainda que em um volume reduzido de dados.

Tabela 8 - Marcadores de TAM restritos a raízes verbais no Emerillon

\begin{tabular}{|c|c|c|c|c|c|}
\hline \multirow{2}{*}{$0^{10^{55^{8}}}$} & \multirow{2}{*}{ Função } & Morfologia & \multirow{2}{*}{ Nomes } & \multirow{2}{*}{ Estados } & \multirow{2}{*}{ Verbos } \\
\hline & & morfemas/alomorfes & & & \\
\hline \multirow{3}{*}{ 主 } & Futuro & -tal & dado elicitado & + & + \\
\hline & Desiderativo & $-\tan \tilde{e}$ & - & + & + \\
\hline & Completivo & $-p a-\sim-b a$ & - & + & + \\
\hline
\end{tabular}

Fonte: elaboração própria

Por tudo o que foi exposto nessa seção, podemos afirmar que os itens lexicais que designam estados parecem apresentar um comportamento morfossintático mais semelhante ao dos verbos intransitivos do que ao dos nomes, ainda que partilhem algumas propriedades com os nomes. Além disso, não pudemos observar entre os chamados nominoides e atributivos um nível de diferenciação 
morfossintática que justifique que essas palavras sejam classificadas de maneira distinta. De fato, a maioria dos atributivos apresentados por Rose (2003) pode predicar de maneira idêntica aos nominoides e há pouquíssimos que apresentam o comportamento diferenciado de serem incompatíveis com a Série II.

É possível que os atributivos sejam um grupo de palavras em mudança, um grupo de verbos intransitivos que está gradualmente perdendo a capacidade de predicar sem o auxílio de ferramentas morfológicas, se diferenciando das outras raízes. Os dois atributivos listados como incompatíveis com a Série II, sin 'branco' ou at "azedo" podem ser palavras que já completaram o ciclo de migração para uma outra classe lexical, mas ainda preservam alguns resíduos de suas antigas propriedades verbais.

Em razão de não termos encontrado diferenças significativas entre as raízes identificadas por Rose (2003) como nominoides e atributivos com relação às raízes verbais desta mesma língua, sugerimos, sem desmerecer a análise realizada responsavelmente por Rose, que os itens lexicais que designam os estados no Emerillón possam, em uma análise alternativa, configurar uma subclasse de verbos intransitivos estativos.

\section{O Guarani}

Em seus estudos sobre línguas da Família TG, Dietrich (2001) não considera a existência de duas classes intransitivas nas diversas variedades do Guaraní que analisa ${ }^{23}$, pois julga como nomes, nessas línguas, as palavras de semantismo adjetival. Por outro lado, para o Guaraní Paraguaio, Mithun (1991), baseada nos dados de Gregores \& Suarez (1967), defende que há uma Cl motivada por parâmetros semânticos. Já a variedade Mbyá foi descrita por Martins (2003) como língua com duas subclasses intransitivas.

Dietrich (2001), citando Coseriu (1972), defende que as classes lexicais no Guaraní - e nas línguas TG como um todo - são fluidas e que todas as classes têm uma predisposição a certas funções sintáticas. Dessa maneira, o autor afirma que "substantivar" um verbo deixa-o preparado para função de sujeito ou objeto, e "verbalizar" um substantivo torna-o apto a predicar, e que no Guaraní isso ocorre sem marcas derivacionais. Partindo de uma determinação semântica para a categorização das palavras, o autor afirma que as línguas TG não possuem classe formal de adjetivos e que a natureza lexical das palavras que denotam qualidades e estados é nominal, já que as línguas TG não distinguem formalmente "a expressão da qualidade branco da expressão da predicatividade nominal da mesma qualidade: isto é, de brancura 'o fato de alguma coisa ser branca (Dietrich $2001: 26)$ ".

Ao caracterizar as classes de palavras em termos formais, Dietrich (op.cit.) explica que há dois grupos de lexemas: um que se combina com

\footnotetext{
${ }^{23}$ Além das variedades do Guaraní, Dietrich (2001) também apresenta exemplos das seguintes línguas da FTG: Siriôno, Mawé, Tembé, Wayampi, Émerillón, Guarayo,
} 
uma determinada série de prefixos de pessoa, e que coincide com o que vem sendo frequentemente denominado Série I, e outro grupo de lexemas que se combina com o que temos chamado de Série II. O primeiro grupo de marcas pessoais Dietrich (2001) associa à classe dos verbos e o segundo exclusivamente a formas nominais.

A explicação fundamental para o autor considerar o primeiro grupo de palavras como verbos é o fato de eles semanticamente exprimirem processos e formalmente se flexionarem com a Série I, diferindo dos substantivos, que possuem o caráter semântico de expressar "substância" e, formalmente, de se flexionarem com as marcas de pessoa da Série II. Dietrich afirma, ainda, que os substantivos podem formar predicados sem se utilizarem de formas verbais, ou seja, eles possuem caráter predicativo quando estão precedidos da marca de pessoa da Série II.

Dietrich (op.cit) afirma que as palavras que designam estados e qualidades costumam ser mal compreendidas em seu contexto em razão de traduções inadequadas para línguas Indo-europeias, incluindo as traduções para o português, que normalmente inserem uma cópula ou um verbo do tipo ser, estar, ter, haver, existir, "tipos de verbos que não existem em Tupí-Guaraní" ${ }^{4}$, e que a tradução dessas palavras como substantivo seria "mais fiel à estrutura sintática do Tupí-Guaraní".

Para justificar a flexão com a série II como marca de P nos verbos transitivos, quando há inversão na hierarquia referencial, e sustentar sua posição de que a Série II é exclusiva dos nomes, Dietrich (2001) postula que esses verbos estejam seguindo o mesmo padrão da sintaxe nominal dessas línguas, que é, segundo o autor, baseada em relação entre um termo e seu dependente, na ordem termo determinante > termo determinado. Assim, afirma que, apesar de a tradução de xe-r-embireko ser tradicionalmente 'minha esposa', a estrutura interna do Guaraní seria outra, sem adjetivo possessivo, querendo dizer 'existe esposa em relação a mim'. Expande, então, essa ideia de determinação aos verbos transitivos com marca de objeto, alegando que uma estrutura como ore roi-pyhy ' $1 \mathrm{pl}$ excl. 2Sg-agarra', não significaria 'nós agarramos você' e sim 'existe agarra com respeito a ti que parte de nós', pois pyhy nesse contexto não seria um verbo transitivo, tampouco roi o seu prefixo verbal, mas o sintagma roi-pyhy inteiro formaria o núcleo determinado por ore:

O que nas línguas européias corresponde a uma construção verbal transitiva com um complemento pronominal de objeto, em Tupí-Guaraní se exprime por um sintagma cujo centro é um lexema que designa ação ou processo, este sem morfema de sujeito (marcador de pessoa verbal), mas determinado por um pronome pessoal de referência. A construção sintática é a do sintagma nominal, não a do verbo precedido do pronome pessoal do objeto. O pronome, neste caso, não é um acusativo (DIETRICH, 2001:31).

\footnotetext{
${ }^{24}$ Há línguas da FTG que apresentam verbos copulativos, tais como o Emerillón e o Kamaiurá, entre outras.
} 
A primeira razão de que nos valemos para contestar o posicionamento de Dietrich (2001) sobre a inexistência de duas subclasses de verbos intransitivos é seu embasamento predominantemente semântico para a questão. Givon (2001:49) afirma que não se pode definir o pertencimento a uma classe por meio de um critério único, mas por pelo menos três grandes conjuntos de critérios: o semântico, que estabelece qual tipo de significado tende a ser codificado por uma classe em particular; o morfológico, que estabelece quais tipos de morfemas presos tendem a se afixar a determinadas classes; e o sintático, que estabelece as posições que palavras de determinadas classes tendem a ocupar na oração.

Não encontramos no artigo de Dietrich (2001) evidências morfossintáticas que corroborem suas afirmações sobre sintaxe nominal e verbal e sobre os aspectos estruturais da língua Guaraní. As afirmações do autor não parecem ser suficientes para explicar a questão dos verbos transitivos quando ele ocorre flexionado com as marcas da Série II, especialmente no que diz respeito a como se dá a alternância de tais raízes classes lexicais, ora como verbo, ao se flexionarem com a Serie I, ora como nomes, ao se flexionarem com a Série II.

Ainda que pudéssemos considerar a proposta de Dietrich (2001) para o Guaraní de alguma maneira parecida com o que ocorre em línguas como o inglês, que exibe a mesma representação formal para nomes e verbos, tal como em I work all day long 'eu trabalho o dia todo' e I have to finish my work 'eu tenho que terminar o meu trabalho', com derivação zero, há que se levar em conta que a forma verbal de uma raiz como work ocorre com uma constelação morfológica e em ambiente sintático específico de formas verbais, enquanto, para funcionar como nome, a mesma raiz vai precisar estar amparada por todo um contexto morfossintático específico de nomes. No caso das línguas TG, tal como são apresentadas por Dietrich (2001), a flexão com as marcas de pessoa das Séries I ou II nos parece ser justificativa insuficiente para estabelecer os contextos morfossintáticos necessários a mudanças de classe lexical com derivação zero.

Obtivemos dados da variedade Mbyá do Guaraní, descrita por Martins (2003), que analisa a classe dos estados como uma subclasse de verbos intransitivos, a que ela denomina descritivos ${ }^{25}$. Morfossintaticamente, os descritivos, conforme Martins (2003), codificam a categoria de pessoa por meio das marcas da Série II, tal como fazem os nomes dependentes para indicar o seu possuidor, e os verbos transitivos, para codificar o argumento objeto. Além disso, os descritivos são considerados uma subclasse de verbos intransitivos no Mbyá pelo fato de, em função predicativa, aceitarem marcadores morfológicos que somente ocorrem com predicados verbais, tais como o marcador de futuro - ta e o nominalizador - $a$ "nome de ação/estado" que ocorre com

\footnotetext{
${ }^{25}$ Segundo a autora, embora os verbos descritivos, em sua maioria, exprimam qualidades e propriedades, podem ser encontrados na língua alguns itens lexicais de comportamento morfossintático idêntico ao dos descritivos, mas com semantismo não adjetival, tais como -ayvu 'falar, -já 'caber' ou 'alcançar', -axe, 'gritar', -monda 'ser ladrão', -koto 'mergulhar', -axuru 'atolar-se'.
} 
verbos transitivos, intransitivos ativos e descritivos, mas não com nomes e elementos de outras classes.

A partir das informações retiradas de Martins (2003), foi possível montar as tabelas 9 e 10, em que podem ser identificados no Mbyá os morfemas que se associam exclusivamente a raízes nominais e a raízes verbais.

Tabela 9 - Morfologia exclusivamente nominal no Guaraní Mbyá

\begin{tabular}{|c|c|c|c|c|c|c|c|}
\hline \multirow{2}{*}{$a^{0^{5^{8}}}$} & \multirow{2}{*}{ Função } & \multirow{2}{*}{$\begin{array}{c}\text { Morfologia } \\
\text { morfemas/alomorfes }\end{array}$} & \multicolumn{2}{|c|}{ Nomes } & \multirow[b]{2}{*}{ Estados } & \multicolumn{2}{|c|}{ Verbos } \\
\hline & & & Absol. & Depen. & & v1 Ativ. & v2 \\
\hline \multirow{3}{*}{ 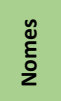 } & Plural & -kuéry, -kue, -gue & + & ? & - & - & - \\
\hline & Passado Nominal & -re & + & + & - & - & - \\
\hline & Futuro Nominal & -rã & + & + & - & - & - \\
\hline
\end{tabular}

Fonte: elaboração própria

Tabela 10 - Morfologia exclusivamente verbal no Guaraní Mbyá

\begin{tabular}{|c|c|c|c|c|c|c|c|}
\hline \multirow{2}{*}{$0^{0^{5^{5}}}$} & \multirow{2}{*}{ Função } & \multirow{2}{*}{$\begin{array}{c}\text { Morfologia } \\
\text { morfemas/alomorfes }\end{array}$} & \multicolumn{2}{|c|}{ Nomes } & \multirow{2}{*}{ Estados } & \multicolumn{2}{|c|}{ Verbos } \\
\hline & & & Absol. & Depen. & & v1 Ativ. & $\mathrm{v}_{2}$ \\
\hline \multirow{5}{*}{ 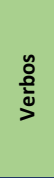 } & Causativização de temas intransitivos & mbo- & - & - & + & + & + \\
\hline & Causativização de temas transitivos & -uka & - & - & - & - & + \\
\hline & Derivação de nomes deverbais & $-a$ & - & - & + & + & + \\
\hline & Futuro & -tá & - & - & + & + & + \\
\hline & Prefixos da Serie I & a-, já-, oro-, ere-, pe-, o- & - & - & - & + & + \\
\hline
\end{tabular}

Fonte: elaboração própria

Assim como nas outras línguas apresentadas neste estudo, é possível observar na Tabela 9 que, no Mbyá, a morfologia atribuída exclusivamente a raízes nominais e, portanto, vetada a raízes verbais, é também vetada às palavras estativas, bem como a Tabela 10 nos mostra a tendência predominante das raízes estativas em se flexionarem com morfemas exclusivos de raízes verbais, com exceção à flexão com as marcas de pessoa da Série I, incompatíveis com as raízes estativas.

\section{ALGUNS RESULTADOS}

O pré-requisito para verificar-se a existência de duas subclasses intransitivas nas línguas TG, uma composta por verbos ativos e outra por estativos, é, justamente, definir a qual das grandes classes formais nome ou verbo - pertencem essas palavras que designam estados. Para isso, foram analisados estudos sobre as línguas TG em busca de informações sobre a morfologia exclusiva de cada classe. As restrições de combinação de verbos e nomes com determinados morfemas foram, então, comparadas com o comportamento das palavras que designam estados, na busca de regularidades que explicitassem sua natureza.

O levantamento dos critérios empregados por cada pesquisador, em cada língua, para classificar as palavras estativas como nomes ou verbos nos levou aos resultados apresentados nas tabelas 11 e 12, que são um resumo de formas cognatas comuns às quatro línguas aqui 
estudadas. É importante observar que a morfologia transcategorial foi descartada por não servir na distinção de classes lexicais.

Tabela 11 - Morfologia exclusivamente nominal comum às quatro línguas

\begin{tabular}{|c|c|c|c|c|c|c|}
\hline$a^{0^{5^{8}}}$ & $\frac{\pi}{2}$ & Função & Tapirapé & Guajá & Emerillón & $\begin{array}{l}\text { Guarani } \\
\text { (Mbyá) }\end{array}$ \\
\hline \multirow{3}{*}{ 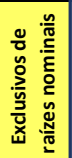 } & 1 & Coletivizador / Plural & -kwer & -kér -ér & -kom & $\begin{array}{l}\text {-kuéry,-kue, } \\
\text {-gue }\end{array}$ \\
\hline & 2 & Passado Nominal & $\begin{array}{l}\text {-kwer, wer, } \\
\text { u-er }\end{array}$ & -kér -ér & \multirow{2}{*}{$n / a$} & -re \\
\hline & & Futuro Nominal & -rym & $-r y m$ & & -rã \\
\hline
\end{tabular}

Fonte: elaboração própria

1) O coletivizador - kwer do Tapirapé e os cognatos -kér e -kuéry do Guajá e do Guaraní, respectivamente, com seus devidos alomorfes, estão associados a raízes nominais. No Guaraní, a distribuição do morfema -kuéry é mais ampla do que no Tapirapé e no Guajá, pois além de raízes nominais, o morfema também se liga a pronomes, o que faz com que ele seja considerado uma marca de plural, tal como Rose (2012) descreve o morfema pluralizador -kom do Emerillón, cuja origem como empréstimo das línguas Caribe foi levada em consideração, mas que optamos por alinhar com a marca de coletivizador/plural TG em razão de sua equivalência funcional e de distribuição.

2) Não foi possível encontrar no trabalho de Rose (2003) referências explícitas sobre a existência dos morfemas de passado e futuro nominal restritos a nomes ou temas nominalizados tal como eles ocorrem no Tapirapé, Guajá e Guaraní. Por sua regularidade em três das quatro línguas estudadas, consideramos esse marcador uma possibilidade para futuras análises.

Tabela 12 - Morfologia exclusivamente verbal comum às quatro línguas

\begin{tabular}{|c|c|c|c|c|c|c|}
\hline $0^{10^{5^{6}}}$ & 营 & Função & Tapirapé & Guajá & Emerillón & $\begin{array}{l}\text { Guarani } \\
\text { (Mbyá) }\end{array}$ \\
\hline \multirow{3}{*}{ 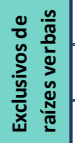 } & 1 & Derivação de nomes deverbais & -ãw -taw & -ahá- -á- & n/a & $-\mathrm{a}$ \\
\hline & 2 & Causativização intransitiva (verbos ativos) & ma- & ma- -mi & bo- mo- & mbo- \\
\hline & 3 & Futuro / Desiderativo & -patãr & -tá & -tal & -tá \\
\hline
\end{tabular}

Fonte: elaboração própria

1) No Emerillón, predominam os processos de nominalização de predicados por meio de sufixação com -mẫ. Segundo Rose (2003), as ocorrências de processos de nominalização de ação, agente, circunstância, instrumento e paciente são atestadas de maneira fragmentada na língua. Por sua regularidade em três das quatro línguas estudadas, consideramos esse marcador importante para futuras análises. 
2) No Tapirapé, o morfema de causativização intransitiva não é exclusivo de raízes verbais, podendo também ocorrer junto a raízes nominais (Praça, em comunicação pessoal). Por sua regularidade em três das quatro línguas estudadas, consideramos esse marcador importante para futuras análises.

3) Os morfemas de futuro e/ou futuro desiderativo aparecem nas quatro línguas associados a temas verbais. No Emerillón o sufixo tal é descrito por Rose (2003) como associado a nomes e verbos, mas produtivamente ele só aparece associado a raízes verbais (e a raízes estativas). As duas ocorrências junto a raízes nominais são coletadas em situação discursiva não espontânea. Por sua regularidade nas outras três línguas, consideramos esse marcador importante para futuras análises.

Nas línguas Tapirapé, Guajá, Emerillón e Guaraní é possível atestar a existência de uma classe relativamente homogênea de palavras que designam estados existenciais, qualidades, propriedades físicas ou psíquicas permanentes ou passageiras e que costumam ser expressas nas línguas Indo-europeias por adjetivos. No entanto, como as línguas TG não costumam possuir uma classe produtiva de adjetivos e como as funções de predicado e argumento não são exclusivas de verbos e nomes, respectivamente, o pertencimento das palavras estativas às grandes classes fica sujeito a diferentes interpretações.

Os resultados desta pesquisa indicam que no Emerillón o comportamento morfossintático das palavras estativas parece ser muito mais assemelhado ao dos verbos intransitivos quando analisamos as possibilidades de combinação dessas raízes com afixos flexionais e derivacionais, e não de predicados inteiros, como foi a opção de Rose (2003) ao descrever a língua. Observa-se, sobre duas subclasses em que teriam se lexicalizados as palavras estativas no Emerillón, que as raízes da subclasse numericamente maior, denominada nominoides, demonstram comportamento morfossintático similar ao dos verbos intransitivos. Já os chamados atributivos, classe menor, parecem apresentar um comportamento um pouco diferente das outras palavras estativas, pois, para exercerem função predicativa, podem se flexionar com as marcas da Série II ou com o sufixo predicativo - $i$.

Em relação ao Guaraní, o artigo de Dietrich (2001) não possui informações suficientes sobre a morfologia da língua, nem dados glosados que possibilitam uma análise detalhada das restrições morfológicas das palavras estativas, já que os argumentos de natureza morfossintática apresentados pelo autor se limitam à possibilidade de flexão das palavras estativas com as marcas da Série II e ao fato de elas poderem exercer função argumental ${ }^{26}$. No entanto, os dados de Martins (2003) para a variedade Mbyá fornecem indícios de que analisar os

\footnotetext{
${ }^{26}$ Sobre o primeiro argumento, há numerosas descrições de línguas TG que associam as marcas da Série II a diversas classes lexicais, incluindo a classe dos verbos; sobre o segundo, como já foi dito anteriormente, não é possível nessas línguas associar com exclusividade as funções de argumento e de predicado às classes de nomes e de verbos.
} 
estados do Guaraní como uma subclasse de verbos intransitivos é uma alternativa bastante viável.

Considerando o número pequeno de línguas analisadas e o fato de termos trabalhado com dados de terceiros, não foi possível confirmar que a classe semântica dos estados se realiza formalmente como verbo em algumas línguas e como nome em outras, o que poderia ser, segundo Queixalós (2001), evidência de que, em perspectiva diacrônica, essas línguas estariam em diferentes estágios de diferenciação das classes nome/verbo a partir de uma antiga super classe de predicados pertencente a uma língua ancestral comum.

Os resultados a que chegamos nas quatro línguas pesquisadas neste trabalho permitem apenas sugerir, a partir da análise apresentada, que as palavras estativas dessas línguas podem compor uma subclasse de verbos intransitivos estativos, e que, apesar das diferenças estruturais entre as línguas, neste aspecto elas tendem a apresentar mais semelhanças do que diferenças. 
Espaço Ameríndio

\section{Referências bibliográficas}

BÚRZIO, L. Intransitive verbs and Italian auxiliaries. Tese de Doutorado, Cambridge, Mass., MIT. 1981.

CABRAL, A. S. Observações sobre a história do morfema -a da família Tupi-Guarani. In: QUEIXALÓS, F. Des nomes et des verbes en Tupi-Guarani: état de la question. Munich: Lincolm Europa, v. 37, 2001. p. 133-162.

CABRAL, A. S. A. C. Caracterização do sistema de alinhamento do Zo'é e o fatores condicionadores de suas múltiplas cisões. Anais do VI Congresso Internacional da Abralin, vol. 2. [S.1.]: [s.n.]. 2006. p. 3145-3153.

COUCHILI, T.; MAUREL, D.; QUEIXALÓS, F. Classes de lexèmes en émérillon. Amerindia, v. 26-27, p. 173-208, 2002.

CREISSELS, D. Remarks on split intransitivity and fluid intransitivity. In: BONAMI, O.; CABREDO HOFNER, P. Empirical Issues in Sintax and Semantics. Paris: CSSP, v. 7, 2008. p. 139-168.

CRUZ, A. D. Fonologia e Gramática do Nheengatú: a língua falada pelos povos Baré, Warekena e Baniwa. Tese de Doutorado (Doutorado em Linguística) Vrije Universiteit. Amsterdan, p. 626. 2011.

DELANCEY, S. Lectures on Functional Syntax. Santa Barbara: LSA Summer Institute, 2001. Disponivel em: <http://pages.uoregon.edu/delancey/sb/fs.html $>$. Acesso em: 14 jan. 2021.

DIETRICH, W. Categorias lexicais nas línguas Tupi-Guarani. In: QUEIXALÓS, F. Des nomes et des verbes en Tupi-Guarani: état de la question. Munich: Lincoln Europa, v. 37, 2001. p. 21-37.

DIXON, R. M. W. Where have all adjectives gone? and other essays in semantics and syntax. Berlin: Mouton de Gruyter, 1982. 1-80 p.

DIXON, R. M. W. Adjective classes in typological perspective. In: AIKHENVALD, S.; DIXON, R. M. W. Adjective classes: a cross linguistic typology. Oxford: Oxford University Press, 2004. p. 1-49.

DONOHUE, M. Semantic alignment systems: what's what and what's not. In:

The typology of semantic alignment. Nova Iorque: Oxford University Press, 2008. p. 24-74.

DOWTY, D. Thematic proto-roles and argument selection. Language, v. 67, n. 3, p. 547619, Set 1991. Disponivel em: <hppt://www.jstor.org/stable/415037>. Acesso em: 26 nov. 2013.

GIVÓN, T. Syntax: an introduction. Amsterdan/Philadelphia: John Benjamins, v. 1, 2001. 
Espaço Ameríndio

GREGORES, E.; SUAREZ, J. A. A description of colloquial Guarani. Amsterdan: Mouton, v. 27, 1967.

KEENAN, E. I. Towards a universal definition of subject. In: LI, C. Subject and Topic. New York: Academic Press, 1976. p. 305-333.

KLIMOV, G. A. On the character of languages of active typology. Linguistics: an international review, Haia, v. 131, p. 11-25, Jan 1974.

LAUNEY, M. Une grammaire omniprédicative: Essai sur la morphosyntaxe du nahuatl classique. Paris: CNRS, 1994.

MAGALHÃES, M. S. Sobre a morfologia e a sintaxe da língua Guajá (Família TupiGuarani). Tese de Doutorado (Doutorado em Linguística) Universidade de Brasília, Instituto de Letras, Departamento de Linguística, Português e Línguas Clássicas. Brasília, p. 297.2007.

MAGALHÃES, M. S.; MATTOS, A. C. R. Classes de palavras, tipos de predicados e sua relação com a intransitividade cindida em Guajá. Via Litterae, Goiânia, v. 6, n. 2, p. 251284, 2014.

MARTINS, M. F. Descrição e análise de aspectos da gramática do Guarani Mbyá. Tese de Doutorado (Doutorado em Linguística) Universidade de Campinas, Instituto de Estudos da Linguagem. Campinas, p. 220. 2003.

MATTOS, A. C. R. A cisão intransitiva em línguas da Família Tupí-Guaraní. Dissertação de Mestrado (Mestrado em Linguística) Universidade de Brasília, Instituto de Letras, Departamento de Linguística, Português e Línguas Clássicas. Brasília, p. 112. 2015 .

MERLAN, F. Split intransitivity: functional oppositions in intransitive inflection. In: NICHOLS, J.; WOODBURY, A. Grammar inside and outside the clause. Londres: Cambridge University Press, 1985. p. 324-363.

MITHUN, M. Active/agentive case marking and its motivations. Language, v. 67, n. 3, p. 510-546, 1994.

PERLMUTTER, D. Impersonal passives and the unaccusative hypothesis. Berkeley Linguistics Society, p. 157-189, 1978.

PRAÇA, W. Morfossintaxe da língua Tapirapé (Família Tupi-Guaraní). Tese de Doutorado (Doutorado em Linguística) Universidade de Brasília, Instituto de Letras, Departamento de Linguística, Português e Línguas Clássicas. Brasília, p. 284. 2007.

QUEIXALÓS. The primacy and fate of predicativity in Tupi-Guarani. In: LOIS, X.; VAPNARSKY, V. Root classes and lexical categories in Amerindian languages. Viena: Peter Lang, 2006. p. 246-287.

QUEIXALÓS, F. Le Tupi-Guarani en chantier. In: QUEIXALÓS, F. Des nomes et des verbes en Tupi-Guarani: état de la question. Munich: Lincoln Europa, v. 37, 2001.p. 01-20. 
Espaço Ameríndio

RODRIGUES, A. D. Relações internas na Família Tupí-Guaraní. Revista de Antropologia, v. 27/28, p. 33-53, 1985.

RODRIGUES, A. D. Argumento e predicado em Tupinambá, p. 57-66, 1996. Disponivel em: $\quad<$ http://biblio.wdfiles.com/local--files/rodrigues-1996argumento/rodrigues_1996_argumento.pdf $>$. Acesso em: 30 nov. 2013.

ROSE, F. Morphossyntaxe de 1'Emerillón. Tese de Doutorado (Doutorado em Ciências da Linguagem) Université Lumière Lyon 2, Faculté des Lettres, Sciences du Langage et Arts. Lyon, p. 680. 2003.

SAPIR, E. Review of Uhlenbeck, C. C., Het passieve Karakter van het Verbum transitivum of van het Verbum actionis in Talen van Noord America (The passive character of the transitive verb or of the active verb in languages of North America). International Journal of American Linguistics, 1917. 82-86.

SEKI, L. Kamaiurá as an active-stative language. In: PAYNE, D. Studies in lowland south american languages. Austin: University of Texas Press, 1990. p. 367-392.

SEKI, L. Gramática do Kamaiurá: língua Tupí-Guaraní do Alto Xingu. Campinas: Editora da Unicamp (Coleção Pesquisas), 2000.

UHLENBECK, C. C. Het Identificeerend Karakter der Possessieve Flexie in Talen van Noord-Amerika ("The Identifying Character of the Possessive Inflection in Languages of North America"). Reprinted from "Verslagen en Mededeelingen der Koninklijke Akademie van Wetenschappen, Amsterdan, 1919. 345-371.

WICHMANN, S. The study of semantic alignment: retrospect and state of art. In: DONOHUE, M. W. S. The typology of semantic alignment. Nova Iorque: Oxford University Press, 2008. p. 3-23.

Recebido em: 17/01/2021 * Aprovado em: 21/03/2021 * Publicado em: 28/04/2021 